\title{
Impaired renal function impacts negatively on vascular stiffness in patients with coronary artery disease
}

\author{
Sabrina H Rossi ${ }^{1}$, Emily P McQuarrie ${ }^{1}$, William H Miller ${ }^{1}$, Ruth M Mackenzie ${ }^{1}$, Jane A Dymott ${ }^{1}$, María U Moreno ${ }^{1,2}$, \\ Chiara Taurino', Ashley M Miller', Ulf Neisius' ${ }^{1}$, Geoffrey A Berg ${ }^{3}$, Zivile Valuckiene ${ }^{3}$, Jonathan A Hannay ${ }^{4}$, \\ Anna F Dominiczak and Christian Delles ${ }^{1 *}$
}

\begin{abstract}
Background: Chronic kidney disease (CKD) and coronary artery disease (CAD) are independently associated with increased vascular stiffness. We examined whether renal function contributes to vascular stiffness independently of CAD status.

Methods: We studied 160 patients with CAD and 169 subjects without CAD. The 4-variable MDRD formula was used to estimate glomerular filtration rate (eGFR); impaired renal function was defined as eGFR $<60 \mathrm{~mL} / \mathrm{min}$. Carotid-femoral pulse wave velocity (PWV) was measured with the SphygmoCor ${ }^{\oplus}$ device. Circulating biomarkers were assessed in plasma using XMAP® multiplexing technology.
\end{abstract}

Results: Patients with CAD and impaired renal function had greater PWV compared to those with CAD and normal renal function $(10.2[9.1 ; 11.2]$ vs $7.3[6.9 ; 7.7] \mathrm{m} / \mathrm{s} ; P<0.001)$. In all patients, PWV was a function of eGFR $(\beta=-0.293$; $P<0.001)$ even after adjustment for age, sex, systolic blood pressure, body mass index and presence or absence of CAD. Patients with CAD and impaired renal function had higher levels of adhesion and inflammatory molecules including E-selectin and osteopontin (all $P<0.05$ ) compared to those with CAD alone, but had similar levels of markers of oxidative stress.

Conclusions: Renal function is a determinant of vascular stiffness even in patients with severe atherosclerotic disease. This was paralleled by differences in markers of cell adhesion and inflammation. Increased vascular stiffness may therefore be linked to inflammatory remodeling of the vasculature in people with impaired renal function, irrespective of concomitant atherosclerotic disease.

Keywords: Coronary artery disease, Chronic kidney disease, Vascular stiffness

\section{Background}

In patients with chronic kidney disease (CKD) cardiovascular risk is at least in part mediated by vascular stiffening. Vascular stiffness increases with progression of CKD [1] and is associated with cardiovascular mortality not only in patients with end stage renal disease (ESRD) [2] but also across all stages of CKD [3]. Vascular stiffness has also been found to be a predictor of decline in renal function in patients with CKD [4]. In patients with

\footnotetext{
* Correspondence: Christian.Delles@glasgow.ac.uk

${ }^{1}$ Institute of Cardiovascular and Medical Sciences, BHF Glasgow

Cardiovascular Research Centre, University of Glasgow, 126 University Place,

G12 8TA, Glasgow, Scotland, UK

Full list of author information is available at the end of the article
}

coronary artery disease (CAD) and normal renal function aortic stiffness is an independent predictor of major cardiac events [5]. Few studies, however, have examined the contribution of renal impairment to vascular stiffness in patients with established atherosclerotic disease. Covic et al. [6] demonstrated that aortic pulse wave velocity predicts the extent and severity of coronary artery disease in patients with CKD. We have previously demonstrated using cardiac magnetic resonance imaging (MRI) that aortic compliance is equally impaired in patients with CAD and in patients with ESRD [7]. More recently, Ilyas et al. [8] demonstrated in patients with various degrees of $\mathrm{CAD}$ that mild renal impairment is associated with increased arterial stiffness.

\section{Ciomed Central}


Inflammation and oxidative stress are key mechanisms in the development of vascular damage in atherosclerosis [9]. The increased vascular stiffness in patients with renal impairment, however, has also been attributed to arterial calcification, inflammation and oxidative stress $[10,11]$. It is unclear if renal impairment leads to acceleration of these mechanisms in patients with atherosclerotic disease. We therefore assessed carotid-femoral pulse wave velocity (PWV) as a direct marker of vascular stiffness in patients with and without CAD and studied whether mild to moderate renal impairment further increases arterial stiffness and if differences in PWV are paralleled by differences in markers of inflammation, cell adhesion and oxidative stress.

\section{Methods}

\section{Participants}

We included 160 patients with severe triple vessel CAD who underwent elective coronary artery bypass graft surgery at the Western Infirmary Glasgow between 2004 and 2008 [7,12-14]. Thirty nine patients with CKD stages 2 to 4 who attend renal clinics at the Western Infirmary Glasgow [15] and 130 healthy control subjects who were recruited from a local sports centre, from a surgical ward in Gartnavel General Hospital Glasgow or were Glasgow University employees, also participated in this study. Hence, a total of 329 subjects, 160 with CAD and 169 without CAD, were studied (Table 1). As a result of rigorous quality checks not all of the parameters below are available in all study participants.
Demographic data were collected and a blood sample was taken to assess lipid profile, CRP, serum creatinine, calcium and phosphate using standard biochemical methods [7]. A lithium-heparinate sample was kept on ice for a maximum of 1 hour prior to centrifugation. Plasma was stored for biomarker analysis at $-80^{\circ} \mathrm{C}$. eGFR was determined using the 4-variable MDRD formula, calibrated to isotope dilution mass spectrometry reference. Impaired renal function was defined as eGFR $<60 \mathrm{~mL} / \mathrm{min}$.

The study adheres to the principles of the Declaration of Helsinki and was approved by the West of Scotland Research Ethics Committee (Reference Number 06/ S0703/110). All participants gave written informed consent.

\section{Pulse wave velocity and analysis}

Carotid-femoral PWV was assessed using the SphygmoCor ${ }^{\circ}$ device (AtCor Medical Ltd., Sydney, Australia) as previously described [16]. A measuring tape was used to assess the distance between the carotid and femoral artery recording sites. PWV was calculated automatically by dividing this distance by the time interval between the rapid upstroke in the pulse wave at the carotid and femoral arteries using the peak of the R-wave on electrocardiography as a reference point.

\section{Circulating markers of oxidative stress}

Oxidised (GSSG) and reduced glutathione levels (GSH) were determined in whole blood using a photometric method (OXIS International Inc., Foster City, California,

Table 1 Characteristics of the study cohort

\begin{tabular}{|c|c|c|c|c|}
\hline & \multicolumn{2}{|c|}{ CAD } & \multicolumn{2}{|c|}{ No CAD } \\
\hline & \multicolumn{2}{|c|}{$n=160$} & \multicolumn{2}{|c|}{$n=169$} \\
\hline & eGFR $\geq 60 \mathrm{~mL} / \mathrm{min}$ & eGFR $<60 \mathrm{~mL} / \mathrm{min}$ & eGFR $\geq 60 \mathrm{~mL} / \mathrm{min}$ & eGFR $<60 \mathrm{~mL} / \mathrm{min}$ \\
\hline & $n=105$ & $n=55$ & $n=119$ & $n=50$ \\
\hline Age (years) & $62.2[60.3 ; 64.1]$ & $69.4[67.5 ; 71.4]$ & $57.0[54.8 ; 59.0]$ & $60.2[56.6 ; 63.8]$ \\
\hline Sex (\% male) & 90 & 49 & 55 & 22 \\
\hline Body mass index $\left(\mathrm{kg} / \mathrm{m}^{2}\right)$ & $28.9[27.9 ; 29.9]$ & $29.7[28.5 ; 30.9]$ & $26.0[25.4 ; 26.7]$ & $28.9[27.1 ; 30.7]$ \\
\hline Active smoking (\%) & 18 & 10 & 10 & 14 \\
\hline Diabetes (\%) & 21 & 35 & 0 & 13 \\
\hline Systolic blood pressure (mmHg) & $138[134 ; 143]$ & $146[139 ; 154]$ & $136[133 ; 139]$ & $143[138 ; 149]$ \\
\hline Diastolic blood pressure $(\mathrm{mmHg})$ & $77[75 ; 79]$ & $78[74 ; 82]$ & $80[78 ; 81]$ & $80[77 ; 84]$ \\
\hline Total cholesterol (mmol/L) & $4.0[3.8 ; 4.2]$ & $3.8[3.5 ; 4.0]$ & $5.6[5.4 ; 5.9]$ & $5.0[4.2 ; 5.8]$ \\
\hline LDL cholesterol (mmol/L) & $2.0[1.9 ; 2.2]$ & $1.8[.16 ; 2.0]$ & $3.4[3.2 ; 3.6]$ & $2.8[2.2 ; 3.4]$ \\
\hline HDL cholesterol (mmol/L) & $1.1[1.0 ; 1.2]$ & $1.2[1.1 ; 1.3]$ & $1.5[1.4 ; 1.6]$ & $1.5[1.2 ; 1.9]$ \\
\hline Serum calcium (mmol/L) & $2.29[2.27 ; 2.31]$ & $2.37[2.30 ; 2.44]$ & $2.35[2.29 ; 2.41]$ & $2.39[2.35 ; 2.42]$ \\
\hline Serum phosphate (mmol/L) & $1.10[1.03 ; 1.16]$ & $1.16[1.05 ; 1.27]$ & $1.06[0.88 ; 1.24]$ & $1.19[1.11 ; 1.27]$ \\
\hline eGFR (mL/min) & $76[73 ; 78]$ & $47[43 ; 50]$ & $82[80 ; 85]$ & $32[28 ; 36]$ \\
\hline
\end{tabular}

CAD coronary artery disease, eGFR estimated glomerular filtration rate, $L D L$ low density lipoprotein, $H D L$ high density lipoprotein. Data are given as mean [95\% confidence interval] or percentages as appropriate. 
USA) as previously described [17]. Oxidised low-density lipoprotein (LDL) cholesterol (oxLDL) was determined using a competitive enzyme-linked immunosorbent assay (Mercodia AB, Uppsala, Sweden).

\section{Circulating biomarkers of inflammation and cell adhesion} Circulating biomarkers were assessed in plasma using three WideScreen multiplex assays (Merck, Nottingham, UK) on a Bio-Plex 100 xMAP platform (Bio-Rad, Hemel Hempstead, UK). WideScreen Human CVD Panel 2 allowed multiplex analysis of interleukin-6 (IL-6), macrophage inflammatory protein-1 alpha (MIP-1 $\alpha$ ), interleukin-8 (IL-8), macrophage inflammatory protein-1 beta (MIP-1 $\beta$ ), monocyte chemoattractant protein 1 (MCP-1) and tumour necrosis factor alpha (TNF- $\alpha$ ). WideScreen Human CVD Panel 3 was used to determine levels of E-selectin, P-selectin, intercellular adhesion molecule-1 (ICAM-1), Leptin, Osteopontin and soluble receptor of advanced glycation end-products (sRAGE). WideScreen Human CVD Panel 6 allowed determination of levels of Adiponectin, extracellular newly identified receptor for advanced glycation end-products binding protein (ENRAGE), plasminogen activator inhibitor-1 (PAI-1), Cystatin $\mathrm{C}$ and vascular cell adhesion molecule-1 (VCAM-1). Plasma samples were removed from $-80^{\circ} \mathrm{C}$ storage, carefully thawed on ice, and prepared (diluted as required) according to the manufacturer's instructions. Analyte levels were recorded from 100 microbeads per area of interest per sample, and each sample was analysed in duplicate using the Bio-Plex system, as per the manufacturer's protocols. Data was processed and analysed using $x$ Ponent $^{\oplus}$ Software (version 3.1.871; Merck, Nottingham, UK). Coefficients of variation were consistent with the manufacturer's published data. Here we only report on biomarkers that passed the quality checks and were detected in plasma of our patients and control subjects; data for Cystatin C, interleukin-6 and MIP-1a did not pass the quality control or were out of the range of the standard curve.

\section{Mononuclear and whole cell superoxide production}

Mononuclear cells were extracted from whole blood as previously described and diluted to $5 \times 10^{6}$ cells $/ \mathrm{mL}$ [18]. Superoxide production was measured in triplicate by electron paramagnetic resonance (EPR) spectroscopy (Bruker BioSpin e-scan R, Bruker Corporation, Rheinstetten, Germany) using the spin probe 1-Hydroxy-3-carboxy2,2,5,5-tetramethylpyrrolidine (CPH; Noxygen, Elzach, Germany) [19]. Maximum superoxide production was assessed after stimulation with phorbol 12-myristate 13acetate (PMA, $3.2 \mu \mathrm{M}$; Sigma-Aldrich, Dorset, UK) and fold changes compared to basal production have been calculated. For assessment of whole blood superoxide generation blood was collected in lithium heparinate containing tubes, kept on ice and processed within half an hour. EPR measurements were performed after adding the spin probe $\mathrm{CPH}$ to a final concentration of $500 \mu \mathrm{mol} / \mathrm{L}$ [12]. Instrument settings were: microwave power, $22 \mathrm{~mW}$; centre field, 3375 G; modulation amplitude, 2.27 G; sweep time, 5.24 s; sweep width, 60 G; 10 scans. Superoxide levels were recorded once a minute for $10 \mathrm{~min}$ and the rate of superoxide anion production was calculated as counts per minute. For mononuclear cells this has been standardised to a rate per $10^{6}$ cells per minute whereas for whole blood arbitrary units (AU) are presented.

\section{Statistical analysis}

Statistical analysis was conducted using SPSS statistical package. Data are presented as mean [95\% confidence interval] or median [interquartile range] as appropriate. Two sample Student's t-test or Mann-Whitney U-test were used to compare data between groups of patients. Correlation was assessed by calculating Pearson's $(r)$ and Spearman's $(\rho)$ correlation coefficients as appropriate.

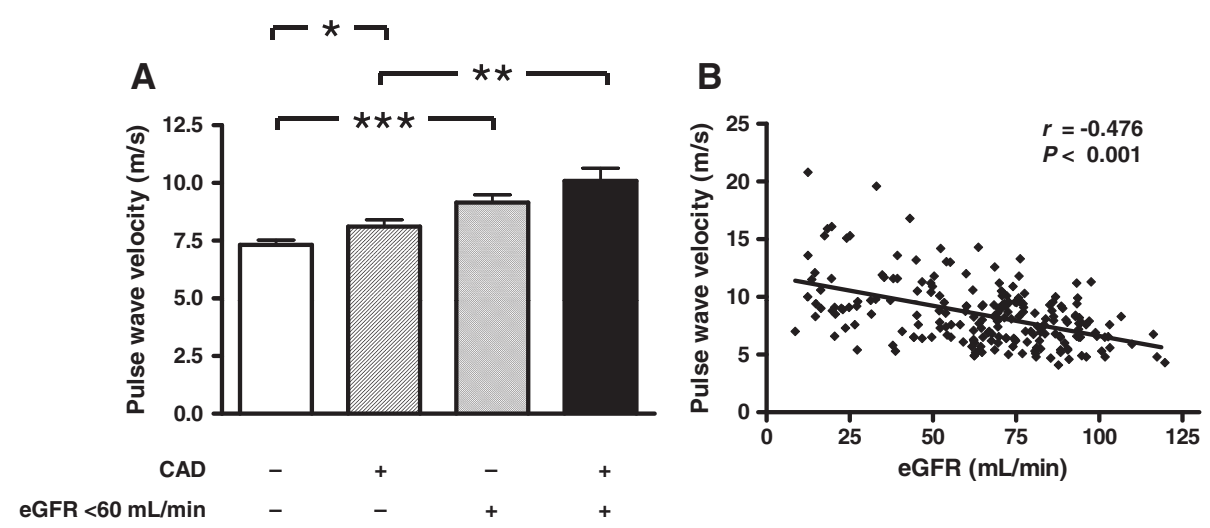

Figure 1 Renal function and pulse wave velocity in the whole study cohort. A Pulse wave velocity in participants with (+) or without (-) coronary artery disease (CAD) and with $(+)$ or without $(-)$ impaired renal function (estimated glomerular filtration rate [eGFR] <60 mL/min). * $P<0.05$, ** $P<0.01 ;{ }^{* *} P<0.001$. B Scatterplot of pulse wave velocity vs eGFR calculated by the MDRD formula. 
Table 2 Markers of oxidative stress

\begin{tabular}{|c|c|c|c|c|c|}
\hline & \multicolumn{3}{|c|}{ CAD } & \multirow{2}{*}{$\begin{array}{c}\text { No CAD } \\
n=93\end{array}$} & \multirow{3}{*}{$\frac{P \text {-value }}{C A D \text { vs no } C A D}$} \\
\hline & \multicolumn{3}{|c|}{$n=100$} & & \\
\hline & $\begin{array}{c}\text { eGFR } \geq 60 \mathrm{~mL} / \mathrm{min} \\
\mathrm{n}=67\end{array}$ & $\begin{array}{c}\text { eGFR }<60 \mathrm{~mL} / \mathrm{min} \\
\mathrm{n}=33\end{array}$ & $P$-value & eGFR $\geq 60 \mathrm{~mL} / \mathrm{min}$ & \\
\hline GSH $(\mu \mathrm{mol} / \mathrm{L})$ & 992 [227] & 894 [399] & 0.067 & $1067[270]$ & 0.001 \\
\hline GSSG ( $\mu \mathrm{mol} / \mathrm{L})$ & $29.0[63.5]$ & $25.6[71.1]$ & 0.904 & $1.94[24.5]$ & $<0.001$ \\
\hline GSH/GSSG ratio & $32.9[569]$ & $32.6[513]$ & 0.636 & 177 [709] & 0.001 \\
\hline OxLDL (AU) & $59.5[35.6]$ & $50.2[33.6]$ & 0.111 & $54.8[24.5]$ & 0.847 \\
\hline OxLDL/LDL ratio $(\mathrm{AU} / \mathrm{mmol} / \mathrm{L})$ & $28.5[16.9]$ & $28.4[10.9]$ & 0.612 & $17.6[5.7]$ & $<0.001$ \\
\hline Whole blood superoxide release ( $\mathrm{nmol} / \mathrm{min} / 10^{6}$ celles) & $1.6[2.2]$ & $1.3[1.0]$ & 0.143 & $1.2[0.6]$ & 0.012 \\
\hline $\begin{array}{l}\text { Basal mononuclear cell superoxide release } \\
\left(\mathrm{nmol} / \mathrm{min} / 10^{6} \text { cells) }\right.\end{array}$ & $2.5[2.0]$ & $2.2[1.8]$ & 0.504 & $1.8[1.0]$ & 0.005 \\
\hline $\begin{array}{l}\text { Maximum (PMA) mononuclear cell superoxide release } \\
\left(\mathrm{nmol} / \mathrm{min} / 10^{6} \mathrm{cells}\right)\end{array}$ & $28.1[21.2]$ & $30.5[23.4]$ & 1.000 & $14.7[9.7]$ & $<0.001$ \\
\hline Fold change in mononuclear cell superoxide release & $12.9[7.1]$ & $15.4[9.2]$ & 0.391 & $8.5[5.4]$ & $<0.001$ \\
\hline
\end{tabular}

CAD coronary artery disease, GSH reduced glutathione, GSSG oxidised glutathione, OxLDL oxidised low density lipoprotein cholesterol, PMA phorbol-12-myristate13-acetate. Data are given as median [interquartile range]. $P$-values are derive from Mann-Whitney U-tests.

Linear regression analysis was performed to show determinants of PWV using both a model where all variables were forced in and then a stepwise model $\left(\mathrm{P}_{\text {in }}<0.05\right.$ and $\left.\mathrm{P}_{\text {out }}>0.10\right)$. For interaction analysis between eGFR and CAD status we centered eGFR around the mean of
eGFR and calculated an interaction term by multiplying centered eGFR with CAD status (coded as $1=$ "no CAD", 2 = "CAD"); these terms were then used in linear regression analysis. A $P$-value of 0.05 (two sided) was considered significant.

Table 3 Circulating biomarkers

\begin{tabular}{|c|c|c|c|c|c|c|}
\hline & \multicolumn{3}{|c|}{ CAD } & \multicolumn{3}{|c|}{ No CAD } \\
\hline & \multicolumn{3}{|c|}{$n=109$} & \multicolumn{3}{|c|}{$\mathrm{n}=86$} \\
\hline & $\begin{array}{c}\text { eGFR } \geq 60 \mathrm{~mL} / \mathrm{min} \\
\mathrm{n}=71\end{array}$ & $\begin{array}{c}\text { eGFR }<60 \mathrm{~mL} / \mathrm{min} \\
\mathrm{n}=38\end{array}$ & $P$-value & $\begin{array}{c}\text { eGFR } \geq 60 \mathrm{~mL} / \mathrm{min} \\
\mathrm{n}=40\end{array}$ & $\begin{array}{c}\text { eGFR }<60 \mathrm{~mL} / \mathrm{min} \\
\mathrm{n}=46\end{array}$ & $P$-value \\
\hline E-selectin (ng/mL) & $10.5[10.4]$ & $17.6[12.6]$ & $<0.001$ & $10.8[6.6]$ & 19.2 [14.2] & $<0.001$ \\
\hline P-selectin (ng/mL) & 90.4 [39.0] & $106.1[57.9]$ & 0.015 & $85.6[45.9]$ & $113.0[45.9]$ & 0.001 \\
\hline ICAM-1 (ng/mL) & $27.6[11.4]$ & 34.5 [21.9] & 0.002 & $23.0[12.6]$ & $33.1[15.6]$ & $<0.001$ \\
\hline VCAM-1 $(\mu \mathrm{g} / \mathrm{mL})$ & $1.37[1.26]$ & $2.03[1.36]$ & 0.006 & $0.96[0.75]$ & $1.42[0.95]$ & 0.008 \\
\hline sRAGE (ng/mL) & $3.8[2.5]$ & $4.8[4.7]$ & 0.110 & $3.8[3.0]$ & $6.7[5.9]$ & $<0.001$ \\
\hline ENRAGE (ng/mL) & $73.2[81.0]$ & $65.3[149.9]$ & 0.794 & $53.9[56.9]$ & $38.3[32.2]$ & 0.059 \\
\hline IL-8 (pg/mL) & $4.0[3.7]$ & $3.8[4.1]$ & 0.218 & $3.2[3.0]$ & $5.1[4.4]$ & 0.005 \\
\hline MCP-1 (pg/mL) & $44.6[31.8]$ & $50.8[48.1]$ & 0.488 & $54.9[40.2]$ & $70.3[53.7]$ & 0.009 \\
\hline MIP-1 $\beta(p g / m L)$ & $66.2[50.4]$ & $73.5[56.5]$ & 0.258 & $66.4[48.2]$ & $95.0[91.1]$ & 0.029 \\
\hline CRP (mg/L) & $2.0[2.2]$ & $2.4[2.9]$ & 0.138 & $1.3[1.9]$ & $2.9[4.8]$ & $<0.001$ \\
\hline TNF-a (pg/mL) & $0.73[1.14]$ & $0.96[1.63]$ & 0.182 & $0.65[0.62]$ & $1.73[1.29]$ & $<0.001$ \\
\hline PAl-1(ng/mL) & $219.0[198.6]$ & $152.5[265.8]$ & 0.329 & $175.8[221.0]$ & $153.8[101.8]$ & 0.044 \\
\hline Adiponectin $(\mu \mathrm{g} / \mathrm{mL})$ & $4.1[3.9]$ & $5.6[6.9]$ & 0.020 & $3.5[4.6]$ & $5.9[9.3]$ & 0.047 \\
\hline Osteopontin(ng/mL) & $0.5[1.0]$ & $1.8[4.0]$ & $<0.001$ & $0.0[0.9]$ & 9.4 [17.9] & $<0.001$ \\
\hline Leptin (ng/mL) & $9.1[8.0]$ & $15.0[27.3]$ & 0.011 & $6.4[9.0]$ & $16.3[28.8]$ & $<0.001$ \\
\hline
\end{tabular}

CAD coronary artery disease, eGFR estimated glomerular filtration rate, ICAM-1 intercellular adhesion molecule-1, VCAM-1 vascular cell adhesion molecule-1, SRAGE soluble receptor of advanced glycation end-products, ENRAGE extracellular newly identified receptor for advanced glycation end-products binding protein $M C P$-1 monocyte chemoattractant protein 1, MIP-1 $\beta$ macrophage inflammatory protein-1 beta, CRP C-reactive protein, TNF- $a$, tumour necrosis factor alpha, $P A l-1$ plasminogen activator inhibitor-1. Data are given as median [interquartile range]. $P$-values refer to comparisons between the eGFR $\geq 60 \mathrm{~mL} / \mathrm{min}$ and eGFR $<60 \mathrm{~mL} / \mathrm{min}$ groups. 


\section{Results}

\section{Study cohort}

Clinical and demographic characteristics of study participants are presented in Table 1. As expected, patients with CAD and/or eGFR $<60 \mathrm{~mL} / \mathrm{min}$ were older than control subjects, and due to lipid-lowering therapy, total and LDL cholesterol levels were lowest in patients with CAD. Blood pressure was similar across the study groups.

\section{Pulse wave velocity}

PWV was greater in patients with eGFR $<60 \mathrm{~mL} / \mathrm{min}$ compared to those with eGFR $\geq 60 \mathrm{~mL} / \mathrm{min}$, both in patients without CAD $(10.2[9.1 ; 11.2]$ vs $7.3[6.9 ; 7.7] \mathrm{m} / \mathrm{s}$; $P<0.001)$ and with CAD $(10.1[8.9 ; 11.2]$ vs $8.1[7.5 ; 8.7]$ $\mathrm{m} / \mathrm{s} ; P=0.001)$. In those with an eGFR $<60 \mathrm{~mL} / \mathrm{min}$, there was no difference in PWV between patients with and without $\operatorname{CAD}(P=0.935)$. In contrast, PWV was greater in the $\mathrm{CAD}$ group when only patients with normal renal function were selected $(P=0.029)$ (Figure 1A).

Assessing eGFR as a continuous variable, a close correlation was found between PWV and eGFR $(r=-0.476$; $P<0.001$ ) in the whole study cohort (Figure 1B). Linear regression analysis demonstrated that eGFR $(\beta=-0.293$; $P<0.001)$ contributed to PWV independently of age $(\beta=0.453 ; \quad P<0.001)$ and systolic blood pressure $(\beta=0.153 ; P=0.009)$; whereas presence or absence of CAD $(\beta=-0.015 ; P=0.798)$, sex $(\beta=0.040 ; P=0.523)$ and body mass index $(\beta=0.064 ; P=0.294)$ did not contribute significantly. A model containing only age, systolic blood pressure and eGFR explained $42 \%$ of the variability of PWV.

Linear regression analysis to study interaction between CAD and eGFR confirmed the key role of eGFR as determinant of PWV. Centered eGFR $(\beta=-0.603, P=$ $0.002)$, but not $C A D$ status $(\beta-0.081 ; P=0.191)$ and the interaction term $(\beta=0.137, P=0.479)$ significantly contributed to the model explaining PWV.

\section{Oxidative stress}

We explored if markers of oxidative stress differed between patients with CAD and those without CAD. In line with our previous observations $[16,17]$ we found significantly increased levels of oxidative stress markers in patients with CAD compared with those without (Table 2). In contrast, no significant differences were found in patients with CAD when stratified into groups with normal or impaired renal function (Table 2). Oxidative stress therefore does not seem to explain the increased vascular stiffness associated with impaired renal function in patients with CAD.

\section{Phosphate and circulating biomarkers of inflammation and cell adhesion}

We then studied circulating biomarkers of inflammation and cell adhesion in control subjects and in patients with
CAD of which both were stratified into groups with normal or impaired renal function. As expected, a number of markers were different between those with and without impaired renal function in the control group (Table 3). In a next step we analysed correlations between these markers and PWV and eGFR in the whole cohort (Table 4). We found that levels of E-selectin, VCAM-1, adiponectin, osteopontin and leptin were consistently different between groups with and without impaired renal function and were correlated with both eGFR and PWV. Scatterplots for these markers illustrating potential correlations that could provide a link between renal function and vascular stiffness are shown in Figure 2.

When added to the multivariate model to study the association of the markers with PWV independently of eGFR, age, systolic blood pressure, sex, presence or absence of CAD and body mass index only E-selectin $(\beta=$ 0.307, $P<0.001$; also included: age $[\beta=0.617, P<0.001]$ ), osteopontin $(\beta=0.336, P<0.001$; also included: age $[\beta=$ $0.538, P<0.001]$, body mass index $[\beta=0.188, P=0.021]$ ) and adiponectin $(\beta=0.203, P=0.017$; also included: age $[\beta=0.502, P<0.001]$, eGFR $[\beta=-0.186, P=0.036]$ and systolic blood pressure $[\beta=0.215, P=0.014]$ ) were part of

Table 4 Correlations between biomarkers and PWV and eGFR

\begin{tabular}{|c|c|c|c|c|}
\hline & & & & \\
\hline & $\rho$ & $P$-value & $\rho$ & $P$-value \\
\hline E-selectin & -0.441 & $<0.001$ & 0.281 & 0.006 \\
\hline P-selectin & -0.272 & $<0.001$ & 0.125 & 0.228 \\
\hline ICAM-1 & -0.541 & $<0.001$ & 0.193 & 0.061 \\
\hline VCAM-1 & -0.264 & $<0.001$ & 0.417 & $<0.001$ \\
\hline sRAGE & -0.369 & $<0.001$ & 0.052 & 0.615 \\
\hline ENRAGE & 0.086 & 0.215 & 0.143 & 0.167 \\
\hline |L-8 & -0.208 & 0.002 & 0.106 & 0.305 \\
\hline MCP-1 & -0.203 & 0.003 & 0.069 & 0.505 \\
\hline MIP-1 $\beta$ & -0.130 & 0.061 & 0.185 & 0.073 \\
\hline C-reactive protein & -0.214 & $<0.001$ & 0.272 & $<0.001$ \\
\hline TNF-a & -0.323 & $<0.001$ & 0.218 & 0.034 \\
\hline PAl-1 & 0.157 & 0.023 & 0.072 & 0.489 \\
\hline Adiponectin & -0.239 & $<0.001$ & .0245 & 0.017 \\
\hline Osteopontin & -0.602 & $<0.001$ & 0.377 & $<0.001$ \\
\hline Calcium & -0.312 & 0.001 & -0.126 & 0.317 \\
\hline Phosphate & 0.977 & $<0.001$ & 0.261 & 0.037 \\
\hline Calcium $\times$ Phosphate & -0.329 & 0.001 & 0.207 & 0.101 \\
\hline Leptin & -0.384 & $<0.001$ & 0.268 & 0.009 \\
\hline
\end{tabular}

eGFR estimated glomerular filtration rate, $P W V$ pulse wave velocity, ICAM-1 intercellular adhesion molecule-1, VCAM-1 vascular cell adhesion molecule-1, sRAGE soluble receptor of advanced glycation end-products, ENRAGE extracellular newly identified receptor for advanced glycation end-products binding protein, $M C P-1$ monocyte chemoattractant protein 1 , MIP-1 $\beta$ macrophage inflammatory protein-1 beta, TNF- $a$ tumor necrosis factor alpha, PAl-1 plasminogen activator inhibitor-1. Spearman correlation coefficients $(\rho)$ and associated $P$-values are given. 
Figure 2 Correlations between renal function, vascular stiffness and circulating biomarkers of inflammation and cell adhesion. Panels $\mathbf{A}$ to $\mathbf{G}$ (left) show scatterplots of E-selectin, vascular cell adhesion molecule-1 (VCAM-1), adiponectin, osteopontin, leptin, C-reactive protein (CRP) and phosphate against estimated glomerular filtration rate (eGFR). Panels $\mathbf{H}$ to $\mathbf{N}$ (right) show scatterplots of pulse wave velocity (PW) against these circulating markers. Data for osteopontin, leptin and CRP have been log transformed for these plots. Open symbols: no coronary artery disease; closed symbols: coronary artery disease. Spearman correlation coefficients and associated $P$-values are displayed in Table 4.

the final models. Of note, the contribution of osteopontin to PWV remained statistically significant even after additional adjustment for phosphate (osteopontin, $\beta=0.206$, $P=0.049$; also included: age $[\beta=0.638, P<0.001]$ and systolic blood pressure $[\beta=0.205 ; P=0.046])$ or calcium (osteopontin, $\beta=0.287, P=0.005$; also included: age $[\beta=$ 0.631, $P<0.001]$ ). Phosphate, CRP, VCAM-1 and leptin were no significant determinants of PWV when adjusted for other factors.

\section{Discussion}

In this study we demonstrate that arterial stiffness is greater in individuals with impaired renal function compared to those with eGFR $\geq 60 \mathrm{~mL} / \mathrm{min}$, even in the presence of advanced CAD. The greater vascular stiffness in the group with impaired renal function was paralleled by differences in markers of inflammation and cell adhesion but not by markers of oxidative stress. We found a close relationship between renal function and PWV, suggesting that renal impairment has an incremental negative effect on arterial stiffness in patients with established CAD. Indeed, impaired renal function was found to be a far stronger determinant of PWV than presence of CAD itself.

\section{Vascular stiffness}

Increased vascular stiffness is an independent predictor of cardiovascular outcome [2,20,21]. Impaired renal function is associated with vascular stiffening, but the underlying mechanisms are incompletely understood [1,10,11,22,23]. From a recent study by Ilyas et al. [8] it appears that there is an additive contribution of impaired renal function to vascular stiffness even in patients with moderately severe CAD. In our present study we have gone one step further and studied patients with severe triple vessel CAD who require surgical revascularisation, compared them with patients without CAD and assessed a wide range of markers of oxidative stress, inflammation and cell adhesion.

We have previously reported reduced aortic compliance in patients with ESRD [7]. In the present study we not only found a linear relationship between renal excretory function and vascular stiffness in mild-to-moderate renal impairment, but also demonstrated that this 
association is independent of other cardiovascular risk factors including systolic blood pressure and age.

\section{Circulating biomarkers and oxidative stress}

Inflammatory processes play an important role in the pathogenesis of vascular disease [9], and renal impairment has been identified as a chronic low grade inflammatory state [11]. The present study demonstrates that levels of E selectin and VCAM-1 are increased in patients with CAD and renal impairment relative to patients with CAD alone. In multivariate analysis only Eselectin was an independent predictor of PWV, and the final model only contained age and E-selectin but not eGFR or blood pressure. It therefore appears plausible, although not directly proven in this cross-sectional study, that effects of impaired renal function on vascular stiffness are at least in part mediated by increased levels of E-selectin. We have previously demonstrated a role of E-selectin in the early stages of pre-eclampsia, a condition that is also associated with renal damage and endothelial dysfunction [24]. Other studies $[25,26]$ reported that adhesion molecules are independent predictors of cardiovascular events in patients with ESRD, although not all studies confirm these data [27]. Adhesion of inflammatory cells to the endothelium is an early step in the development of vascular disease and further induces local vascular inflammation [28].

We have also found independent associations of osteopontin and adiponectin with vascular stiffness. Osteopontin is an extracellular matrix protein that contributes to the development of atherosclerosis as it acts as a proinflammatory cytokine to induce macrophage adhesion and migration, it promotes vascular smooth muscle cell proliferation and may mediate vascular calcification [29]. Osteopontin mRNA is expressed in aortic atherosclerotic plaques in patients with $\mathrm{CAD}$, but not in the arteries of healthy controls, and expression is proportional to severity of disease [30]. In a prospective study of patients with established CAD, osteopontin was an independent predictor of fatal and nonfatal cardiovascular events even after adjustment for traditional risk factors [31]. Lorenzen et al. [29] demonstrated that in patents with CKD, osteopontin levels increase linearly with progressive decline in GFR. Our study suggests that osteopontin levels are further increased in patients with CAD and concomitant renal impairment, and thus may contribute to the development of vascular disease in this group. It is important to note that the association between osteopontin and vascular stiffness in our study was independent of calcium or phosphate levels. The findings on adiponectin are more difficult to interpret. Adiponectin is an adipose tissue-derived protein that is generally thought to have vasoprotective properties. Lower levels of adiponectin have been found in a number of cardiovascular conditions including diabetes [32] and hypertension [33]. On the other hand, renal failure is associated with reduced clearance of adiponectin, and a recently proposed interaction between cystatin $\mathrm{C}$ and adiponectin could explain the paradoxical finding of high adiponectin levels in renal failure and the absence of a vasoprotective effect under these conditions [34].

Oxidative stress has been proposed as a unifying concept to explain the pathophysiology of cardiovascular disease in uraemic patients [11]. We have previously shown that vascular superoxide production is a significant determinant of vascular stiffness in patients without renal disease [16]. Levels of reactive oxygen species are increased in patients with CAD [12,17], but in our present study there was no further rise in oxidative stress to explain the increased vascular stiffness in those with concomitant renal impairment. However, increased expression of adhesion molecules may lead to increased numbers of inflammatory cells in the vessel wall and thereby promote functional and structural changes.

\section{Limitations}

A limitation of our study is that renal impairment was assessed by estimating GFR from serum creatinine using the MDRD equation. eGFR is a measure of renal function which also integrates other important determinants of vascular stiffness, namely age and sex. Without exact measurement of GFR (e.g. by inulin clearance) we cannot precisely separate the effect of renal impairment from that of age on vascular stiffness. However, this issue has been raised in other studies as well and it is not necessarily a limitation [35]. In fact, eGFR captures risk related to a number of characteristics and is an excellent surrogate marker in clinical practice [35,36]. We acknowledge, however, that assessment of renal function at a single time point does not take variability of renal function in response to diet, fluid intake and medication into account.

Another limitation of this study is the cross-sectional design, which precludes inferences about the contribution of renal impairment on vascular stiffness and the effect on future cardiovascular risk, especially as vascular stiffening itself is a process progressing over a long period of time, where improvements of vascular stiffness are associated with improved outcome in patients with CAD [37]; rather we must limit ourselves to showing differences between patient groups. However, vascular stiffness is an established independent predictor of cardiovascular outcome in the general population [38,39], in patients with CAD [21] and in individuals on dialysis $[2,40]$. Recently, Ilyas et al. [8] suggested that assessment of arterial stiffness in patients with established CAD and mild renal impairment has some prospective value, as lower GFR and higher PWV predicted a shorter time to cardiovascular hospitalization and all cause mortality.

We also acknowledge that we did not control for drug therapy in this study. Therefore a number of potentially 
important factors, in particular lipid levels that are affected by statin therapy which is especially prevalent in patients with CAD, may not be adequately represented in our analyses.

Finally, residual confounding is a potential limitation of any study using multivariate analysis. We apreciate that other factors than renal function may have additional effects on vascular stuffness.

\section{Conclusions}

In summary we have demonstrated that even in patients with advanced atherosclerotic disease, concomitant renal impairment is associated with a further increase in vascular stiffness. Our study highlights the pre-eminent role of renal function as a cardiovascular risk factor and justifies efforts to preserve renal function, especially in patients with established cardiovascular diseases. Due to the cross-sectional design, we were unable to demonstrate a direct causal relationship between the changes seen in circulating biomarkers and vascular stiffness. However, the pattern seen suggests that renal impairment may aggravate vascular disease by effects on cell adhesion and inflammation.

\section{Abbreviations}

AU: Arbitrary units; CAD: Coronary artery disease; CKD: Chronic kidney disease; CPH: 1-Hydroxy-3-carboxy- 2,2,5,5-tetramethylpyrrolidine; CRP: Creactive protein; eGFR: Estimated glomerular filtration rate;

ENRAGE: Extracellular newly identified receptor for advanced glycation endproducts binding protein; EPR: Electron paramagnetic resonance; ESRD: End stage renal disease; GSH: Reduced glutathione; GSSG: Oxidised glutathione; IL-6: Interleukin-6; IL-8: Interleukin-8; LDL: Low-density lipoprotein; MCP1: Monocyte chemoattractant protein 1; MIP-1a: Macrophage inflammatory protein-1 alpha; MIP-1 $\beta$ : Macrophage inflammatory protein-1 beta; oxLDL: Oxidised low-density lipoprotein; PAI-1: Plasminogen activator inhibitor-1; PMA: Phorbol 12-myristate 13-acetate; PWV: Pulse wave velocity; SRAGE: Soluble receptor of advanced glycation end-products; TNF-a: Tumour necrosis factor alpha; VCAM-1: Vascular cell adhesion molecule-1. VCAM-1: Vascular cell adhesion molecule-1.

\section{Competing interests}

WHM received support towards travel and accommodation from Merck Chemicals $L t d$. to present preliminary data of this study. There is no other conflict of interest.

\section{Authors' contributions}

Sabrina H Rossi acquired and analysed data; Emily P McQuarrie acquired data, recruited patients with CKD and drafted the manuscript; William H Miller acquired data on markers of inflammation and cell adhesion and drafted the manuscript; Ruth M Mackenzie acquired data on markers of inflammation and cell adhesion; Jane A Dymott acquired data and recruited patients with CAD; María U Moreno acquired data on whole blood and mononuclear cell superoxide production; Chiara Taurino acquired data on whole blood and mononuclear cell superoxide production and recruited patients with CAD; Ashley M Miller acquired data on markers of inflammation and cell adhesion; UIf Neisius acquired data and recruited patients with CAD; Geoffrey A Berg acquired data and recruited patients with CAD; Zivile Valuckiene acquired data and recruited patients with CAD; Jonathan A Hannay acquired data and recruited control subjects; Anna F Dominiczak designed the research; Christian Delles designed the research, acquired and analysed the data, and drafted the manuscript. All authors have critically revised the manuscript and have given final approval of the version to be published.

\section{Acknowledgements}

The authors are grateful to Ms Fiona Jordan and Mr Jim McCulloch for technical assistance. The help of Mr Keith Fourrier with the multiplex experiments and data analysis is gratefully acknowledged. This work was supported by the European Union's Seventh Framework Programme "EU-MASCARA" (grant agreement 278249) and a Strategic Research Development Grant from the Scottish Funding Council.

\section{Author details}

${ }^{1}$ Institute of Cardiovascular and Medical Sciences, BHF Glasgow Cardiovascular Research Centre, University of Glasgow, 126 University Place, G12 8TA, Glasgow, Scotland, UK. ²Division of Cardiovascular Sciences, Center for Applied Medical Research, University of Navarra, Navarra, Spain. ${ }^{3}$ Golden Jubilee National Hospital, Clydebank, UK. ${ }^{4}$ Gartnavel General Hospital, Glasgow, UK.

Received: 18 March 2013 Accepted: 9 August 2013

Published: 13 August 2013

\section{References}

1. Wang MC, Tsai WC, Chen JY, Huang JJ: Stepwise increase in arterial stiffness corresponding with the stages of chronic kidney disease. Am J Kidney Dis 2005, 45:494-501.

2. Blacher J, Guerin AP, Pannier B, Marchais SJ, Safar ME, London GM: Impact of aortic stiffness on survival in end-stage renal disease. Circulation 1999, 99:2434-2439.

3. Karras A, Haymann JP, Bozec E, Metzger M, Jacquot C, Maruani G, Houillier $P$, Froissart M, Stengel B, Guardiola $P$, et al: Large artery stiffening and remodeling are independently associated with all-cause mortality and cardiovascular events in chronic kidney disease. Hypertension 2012, 60:1451-1457.

4. Chen SC, Chang JM, Liu WC, Tsai YC, Tsai JC, Hsu PC, Lin TH, Lin MY, Su HM, Hwang SJ, et al: Brachial-ankle pulse wave velocity and rate of renal function decline and mortality in chronic kidney disease. Clin J Am Soc Nephrol 2011, 6:724-732.

5. Tomiyama H, Koji Y, Yambe M, Shiina K, Motobe K, Yamada J, Shido N, Tanaka N, Chikamori T, Yamashina A: Brachial-ankle pulse wave velocity is a simple and independent predictor of prognosis in patients with acute coronary syndrome. Circ J 2005, 69:815-822.

6. Covic A, Haydar AA, Bhamra-Ariza P, Gusbeth-Tatomir P, Goldsmith DJ: Aortic pulse wave velocity and arterial wave reflections predict the extent and severity of coronary artery disease in chronic kidney disease patients. J Nephrol 2005, 18:388-396.

7. Zimmerli LU, Mark PB, Steedman T, Foster JE, Berg GA, Dargie HJ, Jardine $A G$, Delles $C$, Dominiczak AF: Vascular function in patients with end-stage renal disease and/or coronary artery disease: a cardiac magnetic resonance imaging study. Kidney Int 2007, 71:68-73.

8. Ilyas B, Dhaun N, Markie D, Stansell P, Goddard J, Newby DE, Webb DJ: Renal function is associated with arterial stiffness and predicts outcome in patients with coronary artery disease. QJM 2009, 102:183-191.

9. Packard RR, Libby P: Inflammation in atherosclerosis: from vascular biology to biomarker discovery and risk prediction. Clin Chem 2008, 54:24-38.

10. Toussaint ND, Lau KK, Strauss BJ, Polkinghorne KR, Kerr PG: Associations between vascular calcification, arterial stiffness and bone mineral density in chronic kidney disease. Nephrol Dial Transplant 2008, 23:586-593.

11. Himmelfarb J, Stenvinkel P, Ikizler TA, Hakim RM: The elephant in uremia: oxidant stress as a unifying concept of cardiovascular disease in uremia. Kidney Int 2002, 62:1524-1538.

12. Delles C, Dymott JA, Neisius U, Rocchiccioli JP, Bryce GJ, Moreno MU, Carty DM, Berg GA, Hamilton CA, Dominiczak AF: Reduced LDL-cholesterol levels in patients with coronary artery disease are paralleled by improved endothelial function: an observational study in patients from 2003 and 2007. Atherosclerosis 2010, 211:271-277.

13. Berry C, Zimmerli LU, Steedman T, Foster JE, Dargie HJ, Berg GA Dominiczak AF, Delles C: Cardiac magnetic resonance findings predict increased resource utilization in elective coronary artery bypass grafting. Clin Sci (Lond) 2008, 114:423-430.

14. Taurino C, Miller WH, McBride MW, McClure JD, Khanin R, Moreno MU, Dymott JA, Delles C, Dominiczak AF: Gene expression profiling in whole blood of patients with coronary artery disease. Clin Sci (Lond) 2010, 119:335-343. 
15. McQuarrie EP, Patel RK, Mark PB, Delles C, Connell J, Dargie HJ, Steedman T, Jardine AG: Association between proteinuria and left ventricular mass index: a cardiac MRI study in patients with chronic kidney disease. Nephrol Dial Transplant 2010, 26:933-938.

16. Delles C, Zimmerli LU, McGrane DJ, Koh-Tan CH, Pathi VL, McKay AJ, Steedman T, Dargie HJ, Hamilton CA, Dominiczak AF: Vascular stiffness is related to superoxide generation in the vessel wall. J Hypertens 2008, 26:946-955.

17. Al Benna S, Hamilton CA, McClure JD, Rogers PN, Berg GA, Ford I, Delles C, Dominiczak AF: Low-density lipoprotein cholesterol determines oxidative stress and endothelial dysfunction in saphenous veins from patients with coronary artery disease. Arterioscler Thromb Vasc Biol 2006, 26:218-223.

18. Fortuno A, Olivan S, Beloqui O, San Jose G, Moreno MU, Diez J, Zalba G: Association of increased phagocytic NADPH oxidase-dependent superoxide production with diminished nitric oxide generation in essential hypertension. J Hypertens 2004, 22:2169-2175.

19. Fink B, Dikalov $S$, Bassenge E: A new approach for extracellular spin trapping of nitroglycerin-induced superoxide radicals both in vitro and in vivo. Free Radic Biol Med 2000, 28:121-128.

20. Boutouyrie P, Tropeano Al, Asmar R, Gautier I, Benetos A, Lacolley P, Laurent S: Aortic stiffness is an independent predictor of primary coronary events in hypertensive patients: a longitudinal study. Hypertension 2002, 39:10-15.

21. Chirinos JA, Zambrano JP, Chakko S, Veerani A, Schob A, Willens HJ, Perez G, Mendez AJ: Aortic pressure augmentation predicts adverse cardiovascular events in patients with established coronary artery disease. Hypertension 2005, 45:980-985.

22. Kawamoto R, Kohara K, Tabara Y, Miki T, Ohtsuka N, Kusunoki T, Yorimitsu N: An association between decreased estimated glomerular filtration rate and arterial stiffness. Intern Med 2008, 47:593-598.

23. Schillaci G, Pirro M, Mannarino MR, Pucci G, Savarese G, Franklin SS, Mannarino E: Relation between renal function within the normal range and central and peripheral arterial stiffness in hypertension. Hypertension 2006, 48:616-621.

24. Carty DM, Anderson LA, Freeman DJ, Welsh PI, Brennand JE, Dominiczak AF, Delles C: Early pregnancy soluble E-selectin concentrations and risk of preeclampsia. J Hypertens 2012, 30:954-959.

25. Suliman ME, Qureshi AR, Heimburger O, Lindholm B, Stenvinkel P: Soluble adhesion molecules in end-stage renal disease: a predictor of outcome. Nephrol Dial Transplant 2006, 21:1603-1610.

26. Tripepi G, Mallamaci F, Zoccali C: Inflammation markers, adhesion molecules, and all-cause and cardiovascular mortality in patients with ESRD: searching for the best risk marker by multivariate modeling. J Am Soc Nephrol 2005, 16 Suppl 1:S83-8:S83-S88.

27. Malatino LS, Stancanelli B, Cataliotti A, Bellanuova I, Fatuzzo P, Rapisarda F, Leonardis D, Tripepi G, Mallamaci F, Zoccali C: Circulating E-selectin as a risk marker in patients with end-stage renal disease. J Intern Med 2007, 262:479-487.

28. Ross R: Atherosclerosis-an inflammatory disease. N Engl J Med 1999 340:115-126.

29. Lorenzen J, Kramer R, Kliem V, Bode-Boeger SM, Veldink H, Haller H, Fliser D, Kielstein JT: Circulating levels of osteopontin are closely related to glomerular filtration rate and cardiovascular risk markers in patients with chronic kidney disease. Eur J Clin Invest 2010, 40:294-300.

30. Ikeda T, Shirasawa T, Esaki Y, Yoshiki S, Hirokawa K: Osteopontin mRNA is expressed by smooth muscle-derived foam cells in human atherosclerotic lesions of the aorta. J Clin Invest 1993, 92:2814-2820.

31. Minoretti P, Falcone C, Calcagnino M, Emanuele E, Buzzi MP, Coen E, Geroldi $D$ : Prognostic significance of plasma osteopontin levels in patients with chronic stable angina. Eur Heart J 2006, 27:802-807.

32. Hotta K, Funahashi T, Arita Y, Takahashi M, Matsuda M, Okamoto Y, Iwahashi $\mathrm{H}$, Kuriyama H, Ouchi N, Maeda K, et al: Plasma concentrations of a novel, adipose-specific protein, adiponectin, in type 2 diabetic patients. Arterioscler Thromb Vasc Biol 2000, 20:1595-1599.

33. Delles C, Raff U, Mimran A, Fauvel JP, Ruilope LM, Schmieder RE: Effects of telmisartan and ramipril on adiponectin and blood pressure in patients with type 2 diabetes. Am J Hypertens 2008, 21:1330-1336.

34. Komura N, Kihara S, Sonoda M, Maeda N, Tochino Y, Funahashi T, Shimomura I: Increment and impairment of adiponectin in renal failure. Cardiovasc Res 2010, 86:471-477.

35. Drury PL, Ting R, Zannino D, Ehnholm C, Flack J, Whiting M, Fassett R, Ansquer JC, Dixon P, Davis TM, et al: Estimated glomerular filtration rate and albuminuria are independent predictors of cardiovascular events and death in type 2 diabetes mellitus: the Fenofibrate Intervention and Event Lowering in Diabetes (FIELD) study. Diabetologia 2011, 54:32-43.

36. Delles C, Jardine AG: Renal function and cardiovascular events: relevance of eGFR and albuminuria in patients with diabetes. Diabetologia 2011, 54:4-6.

37. Orlova IA, Nuraliev EY, Yarovaya EB, Ageev FT: Prognostic value of changes in arterial stiffness in men with coronary artery disease. Vasc Health Risk Manag 2010, 6:1015-1021.

38. Mitchell GF, Hwang SJ, Vasan RS, Larson MG, Pencina MJ, Hamburg NM, Vita JA, Levy D, Benjamin EJ: Arterial stiffness and cardiovascular events: the Framingham heart study. Circulation 2010, 121:505-511.

39. Mattace-Raso FU, van der Cammen TJ, Hofman A, Van Popele NM, Bos ML, Schalekamp MA, Asmar R, Reneman RS, Hoeks AP, Breteler MM, et al: Arterial stiffness and risk of coronary heart disease and stroke: the Rotterdam study. Circulation 2006, 113:657-663.

40. Blacher J, Safar ME, Pannier B, Guerin AP, Marchais SJ, London GM: Prognostic significance of arterial stiffness measurements in end-stage renal disease patients. Curr Opin Nephrol Hypertens 2002, 11:629-634.

doi:10.1186/1471-2369-14-173

Cite this article as: Rossi et al.: Impaired renal function impacts negatively on vascular stiffness in patients with coronary artery disease. BMC Nephrology 2013 14:173.

\section{Submit your next manuscript to BioMed Central and take full advantage of:}

- Convenient online submission

- Thorough peer review

- No space constraints or color figure charges

- Immediate publication on acceptance

- Inclusion in PubMed, CAS, Scopus and Google Scholar

- Research which is freely available for redistribution 